\title{
In vitro SEM analysis of desensitizing agents and experimental hydroxyapatite-based composition effectiveness in occluding dentin tubules
}

\author{
Łukasz Rafał Pałka ${ }^{1, A-F}$, Zbigniew Rybaka, ${ }^{1, A, C, E, F}$, Piotr Kuropka ${ }^{2, C, F}$, \\ Maria Krystyna Szymonowicz',B, , Jan Kiryk ${ }^{3, B, C}$, Krzysztof Maryc ${ }^{4, B, C}$, Maciej Dobrzyński ${ }^{5, A-D}$ \\ ${ }^{1}$ Department of Experimental Surgery and Biomaterials Research, Wroclaw Medical University, Poland \\ ${ }^{2}$ Department of Animal Physiology and Biostructure, Wrocław University of Environmental and Life Sciences, Poland \\ ${ }^{3}$ Department of Dental Surgery, Wroclaw Medical University, Poland \\ ${ }^{4}$ Department of Experimental Biology, Wrocław University of Environmental and Life Sciences, Poland \\ ${ }^{5}$ Department of Conservative Dentistry and Pedodontics, Wroclaw Medical University, Poland \\ A - research concept and design; $\mathrm{B}$ - collection and/or assembly of data; $\mathrm{C}$ - data analysis and interpretation; \\ $D$ - writing the article; $E$ - critical revision of the article; $F$ - final approval of the article
}

Address for correspondence

Łukasz Rafał Pałka

E-mail: regmed.klinika@gmail.com

\section{Funding sources}

This study was supported by a "Grant PLUS" provided by the Marshall's Office of the Lower Silesian Region in Wroctaw, directed by Łukasz Pałka.

Conflict of interest

None declared

Received on April 16, 2020

Reviewed on August 22, 2020

Accepted on October 7, 2020

Cite as

Pałka ŁR, RybakZ, Kuropka P, et al. In vitro SEM analysis of desensitizing agents and experimental hydroxyapatitebased composition effectiveness in occluding dentin tubules. Adv Clin Exp Med. 2020;29(11):1283-1297.

doi:10.17219/acem/128197

D0I

10.17219/acem/128197

Copyright

Copyright by Author(s)

This is an article distributed under the terms of the

Creative Commons Attribution 3.0 Unported (CC BY 3.0)

(https://creativecommons.org/licenses/by/3.0/)

\begin{abstract}
Background. Novel materials used for dentin hypersensitivity (DH) treatment, including hydroxyapatitebased desensitizers, are not only effective in occluding dentinal tubules, but are also biocompatible and non-toxic. A newly formulated desensitizer containing hydroxyapatite was evaluated in comparison to commercially available desensitizers.

Objectives. To compare the occluding efficacy and durability of 3 commercially available desensitizing agents with a pharmaceutical composition developed by the authors based on hydroxyapatite (HAp).

Material and methods. For the experiment, 40 disc-shaped dentin specimens ( $5 \mathrm{~mm}$ thick) were obtained from extracted human teeth. Each disc was divided into 4 sections, so that each desensitizing agent could be applied to each specimen and prepared for further evaluation in most homogenous conditions. The chemical composition of the dentin surfaces was analyzed using scanning electron microscopy (SEM) equipped with an energy-dispersive X-ray spectroscope (EDS), Fourier-transform infrared (FTIR) and Raman spectra techniques. The specimens were immersed in an artificial saliva solution for $24 \mathrm{~h}, 48 \mathrm{~h}$ and 7 days to assess the durability of the layers and the tubule-obliteration effectiveness. Data analysis was performed using Student's t-test with an average value of normal distribution at an unknown variance with a standard deviation (SD) of $0-0.4$.
\end{abstract}

Results. All the test groups showed some degree of dentinal tubule occlusion or a covering layer, but the HApbased composition proved to be the longest-lasting. It was concluded that the developed pharmaceutical composition creates a coating on the dentin surface built of hydroxyapatite crystals sized 10-20 $\mathrm{mm}$, which are likely to constitute a reservoir of calcium and phosphate ions, as well as smaller crystals $(0.2-0.3 \mu \mathrm{m})$ that occlude dentinal tubules.

Conclusions. The composition containing biocompatible hydroxyapatite effectively occluded dentinal tubules and therefore exhibits a potential for reducing the pain and discomfort caused by dentin hypersensitivity.

Key words: scanning electron microscopy, dental material, dentin hypersensitivity, dentin tubules, hydroxyapatite 


\section{Introduction}

One of the many sensations accompanying us throughout our lifetime is pain. This physical sensation warns us against any violation of physiological barriers or events exceeding the adaptive possibilities of our bodies and body structures, including teeth. A healthy tooth consists of a well innervated and vascularized pulp, dentin, enamel, and cement. If physical, chemical or iatrogenic factors damage this structure, it causes pain, which may become unbearable and force patients to seek specialized help. Tooth hypersensitivity, or more appropriately dentin (or dentinal) hypersensitivity (DH), is defined as an excessive response to harmless external stimuli, ${ }^{1}$ which, according to researchers, affects as many as $74-80 \%$ of the adult population, depending on the geographical region. ${ }^{2,3}$

According to hydrodynamic theories, any restriction of tubular fluid movement contributes to the reduction of $\mathrm{DH} .{ }^{4}$ There are 2 main chairside approaches for treating DH: the obliteration of dentin tubules to reduce tubular fluid movement, and desensitization of nerves to reduce their sensitivity to stimuli. ${ }^{5,6}$ Nerves can be desensitized with the use of potassium nitrate, and dentin tubules can be occluded with, e.g., glutaraldehyde, silver nitrate or zinc chloride, sealed by dentinal adhesives, or by laser (Nd:YAG, GaAlAs, Er:YAG). ${ }^{7-14}$

To date, numerous studies have been conducted with different active ingredients such as strontium chloride, potassium nitrate, potassium, iron and aluminum oxalates, bioactive glass, sodium citrate, potassium citrate, calcium hydroxyapatite, glutaraldehyde, potassium bicarbonate, cyanoacrylates, strontium chloride, calcium hydroxide, and silver nitrate in search of a perfect solution for $\mathrm{DH} .{ }^{15-}$ 18 Among these materials, nanohydroxyapatite (nHAp) is believed to be one of the most effective treatment options. Its biocompatibility and bioactive nature have been widely used in medicine and dentistry. ${ }^{19,20}$ Hydroxyapatite is a crystallized nonorganic calcium compound that is biocompatible and a natural constituent of bones and teeth, and it has gained acceptance in treating $\mathrm{DH}$ in recent years. There are many in vitro and clinical studies that have reported the effective dentin occlusion capabilities of nHAp. ${ }^{19-25}$

The aim of this in vitro study was to develop a novel biocompatible, non-toxic hydroxyapatite-based agent that could be used in restorative dentistry.

\section{Material and methods}

This study was based on chemical and radiographic examinations. The experiment protocol was approved by the Bioethics Committee at Wroclaw Medical University (Poland), approval No. KB 230/2014, and has been conducted in full accordance with the World Medical Association Declaration of Helsinki. The experimental part of this study included selected desensitizing agents that are known for their obliterating features (Isodan $^{\circledR}$, Bifluorid ${ }^{\circledR}$, Cervitec $^{\circledR}$ ) and are commonly used in dentistry, as well as a hydroxyapatite-based composition developed by the authors.

\section{Preparation of the HAp-based composition}

The present study aimed to create a composition obliterating dentinal tubules with the use of substances that may be metabolized by the cells present in the proximity and inside the tooth. The newly formulated desensitizer consisted of hydroxyapatite (Nanosynhap, Poznań, Poland), citric acid and glycerol in a self-developed molar ratio. It was prepared by mixing citric acid with glycerol and then incubating it at $100^{\circ} \mathrm{C}$ for $24 \mathrm{~h}$. After this time, the $\mathrm{pH}$ of the mixture was measured; it ranged from 1.5 to 3.0. In the next step, calcium hydroxyapatite was added in the amount of $5-10 \%$ of the mixture weight. Tubes with the mixture were mounted on an IKA MS 3 basic mixer (IKA-Werke GmbH, Staufen im Breisgau, Germany) and mixed for $20 \mathrm{~s}$. Then it was reheated at $100^{\circ} \mathrm{C}$ for $10 \mathrm{~h}$. The $\mathrm{pH}$ of the mixture ranged from 2.45 to 4.19 .

\section{Infrared spectra}

Infrared spectra in the $4000-400 \mathrm{~cm}^{-1}$ range were measured using a Vertex 70V Fourier-transform infrared spectroscopy (FTIR) vacuum spectrometer (Brüker Corp., Billerica, USA) for the self-developed composition at different concentrations. The measurements were made with the attenuated internal reflection technique, using a single-reflection ATR with a diamond crystal in vacuum conditions.

\section{Raman spectra}

After analyzing the infrared spectra and literature reports, we decided to perform additional Raman spectra measurements on the same samples. Raman spectra were measured on a Multi-RAM FT-Raman spectrometer (Brüker Corp.) equipped with a germanium detector. The samples were induced with a $1064 \mathrm{~nm}$ wavelength laser (Nd:YAG). The measurements were made in the $3600-50 \mathrm{~cm}^{-1}$ spectral range, with a resolution of $4 \mathrm{~cm}^{-1}$; the number of scans was 256 , with laser power on a $500 \mathrm{~mW}$ sample.

\section{Desensitizing agents and artificial saliva}

The commercially-available desensitizing agents included in the study were Isodan ${ }^{\circledR}$, Bifluorid ${ }^{\circledR}$ and Cervitec ${ }^{\circledR}$. Isodan ${ }^{\circledR}$ (Septodont Corp., Saint-Maur-des-Fossés, France) is a multi-compound product in the form of a gel that consists of 2-hydroxyethyl methacrylate, potassium nitrate and sodium fluoride. Bifluorid $10^{\circledR}$ (Voco GmbH, Cuxhaven, Germany) is a fluoride varnish that contains $5 \%$ sodium fluoride and 5\% calcium fluoride. Cervitec ${ }^{\circledR}$ (Ivoclar 
Vivadent AG, Schaan, Liechtenstein) is a varnish consisting of chlorhexidine and thymol.

We used a buffered solution of artificial saliva commonly used for experiments, with $\mathrm{pH} 6.7$, in $\mathrm{g} / \mathrm{dm}^{3}$, consisting of $\mathrm{K}_{2} \mathrm{HPO}_{4}(0.20)$; $\mathrm{Na}_{2} \mathrm{HPO}_{4}(0.26)$; $\mathrm{KSCN}(0.33)$; $\mathrm{NaHCO}_{3}$ (1.5); $\mathrm{NaCl}(0.70) ; \mathrm{CO}\left(\mathrm{NH}_{2}\right) 2$ (0.13); $\mathrm{KCl}(1.2)$.

\section{Preparation of the teeth}

Forty human teeth extracted due to orthodontic indications were used to assess the tubule occluding effectiveness of the desensitizers. Under macroscopic evaluation, the teeth appeared fully developed, without caries or enamel damage, and free of dental fillings. They were cleaned of any tissue residue, blood and saliva, and rinsed in $\mathrm{NaCl}$. After drying at room temperature, each tooth was sectioned using a diamond separator (ST-DD $22 \times 0$; Falcon Medical, Lucca, Italy) under constant water cooling to obtain $2 \mathrm{~mm}$-thick enamel-dentin discs. The external layer of the enamel was removed to expose the dentin using turbine diamond drills and Sof-Lex polishing discs (3M ESPE, Saint Paul, USA) to obtain homogeneous, flat and smooth surfaces. Selected discs were polished and rinsed in demineralized water for $5 \mathrm{~min}$, and then etched in $40 \%$ citric acid for $1 \mathrm{~min}$ to remove the smear layer and open dentinal tubules to simulate DH. Afterward, they were washed in demineralized water and rinsed in an ultrasound washer for $10 \mathrm{~min}$ to remove any contaminations. Each of the discs was sectioned horizontally and vertically, as described in earlier studies, ${ }^{26-29}$ and divided in 4 equal parts (Fig. 1) to compare the tested desensitizers on each tooth in similar conditions. The substances under investigation were then applied to the surfaces of the open tubules, as in the description shown in Fig. 1.

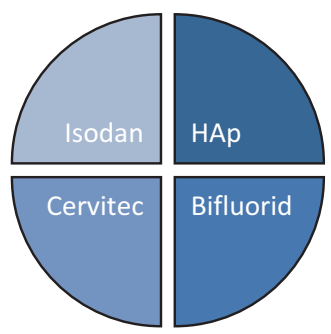

Fig. 1. Dentin disc with desensitizing agents

\section{SEM surface examination}

The samples were observed at $\times 500, \times 1000, \times 2000$, and $\times 5000$ magnification using an $\mathrm{EVO}^{\circledR}$ LS 15 scanning electron microscope (SEM) (Carl Zeiss, Oberkochen, Germany). Before the images were taken, a gold layer was sprayed onto the test specimens using the EDWARDS SCANCOAT Six device (BOC Edwards, West Sussex, UK).

The SEM examination was performed before applying the desensitizing materials, immediately after applying them, and after $24 \mathrm{~h}$ and $48 \mathrm{~h}$ of immersion in the artificial saliva solution. After 7 days of immersion in the artificial saliva, a SEM examination of the sample with the HApbased formulation was carried out. Each of the images representing the tooth surface was investigated in terms of the agent used (B-Bifluorid ${ }^{\circledR}, \mathrm{C}-$ Cervitec $^{\circledR}, \mathrm{H}$-Hydroxyapatite, I-Isodan $\left.{ }^{\circledR}\right)$ and the elapsed time $(0 \mathrm{~h}, 24 \mathrm{~h}, 48 \mathrm{~h}$, $168 \mathrm{~h}$ ) to analyze the dynamics of the changes.

\section{Examination of the dentin disc surface}

The extent of tubule occlusion was assessed by a trained examiner grading the SEM images. Each of the discs was divided into 4 sections, as shown in Fig. 1, to conduct a comparative assessment of the obliterating ability of the 3 commercial desensitizers and our own composition. Specific regions of each specimen were covered with the desensitizing agents according to the manufacturer's instructions, while our own composition was rubbed into the disc surface using a micro brush for $10 \mathrm{~s}$ and left to dry. After the treatment, the specimens were prepared for analysis with SEM.

\section{Statistical analysis of the diameter of the dentinal tubules}

In the study, 8 tooth surface sets with 6 samples in sets 1-7 and 3 samples in set 8 were randomly selected from among the tubules visible on 8 representative SEM photographs. The t-test was used to test the null hypothesis, which assumed a mean value $\geq 3$ and standard deviation (SD) $\sigma-0.4$.

\section{Results}

\section{FTIR spectra}

When analyzing the FTIR spectra of the individual components, we observed that the calcium phosphate (V) vibration bands were obscured by the bands derived from citric acid and glycerol. In particular, the range of $\mathrm{Ca}_{3}\left(\mathrm{PO}_{4}\right)^{2}$ bands is in the area in which we observed glycerol vibration bands. This method did not give us information on the qualitative composition of the self-developed mixture, and we could not determine the change in the calcium phosphate $(\mathrm{V})$ form in the analyses.

\section{Raman spectra}

After analyzing infrared spectra, we decided to measure Raman spectra on a Multi-RAM FT-Raman spectrometer (Brüker Corp.) equipped with a germanium detector. The samples were excited with a $1064 \mathrm{~nm}$ wavelength laser (Nd:YAG). The measurements were performed in the 3600$50 \mathrm{~cm}^{-1}$ spectral range, with a resolution of $4 \mathrm{~cm}^{-1}, 256 \mathrm{scans}$ per sample, and a laser power of $500 \mathrm{~mW} / \mathrm{sample}$. 


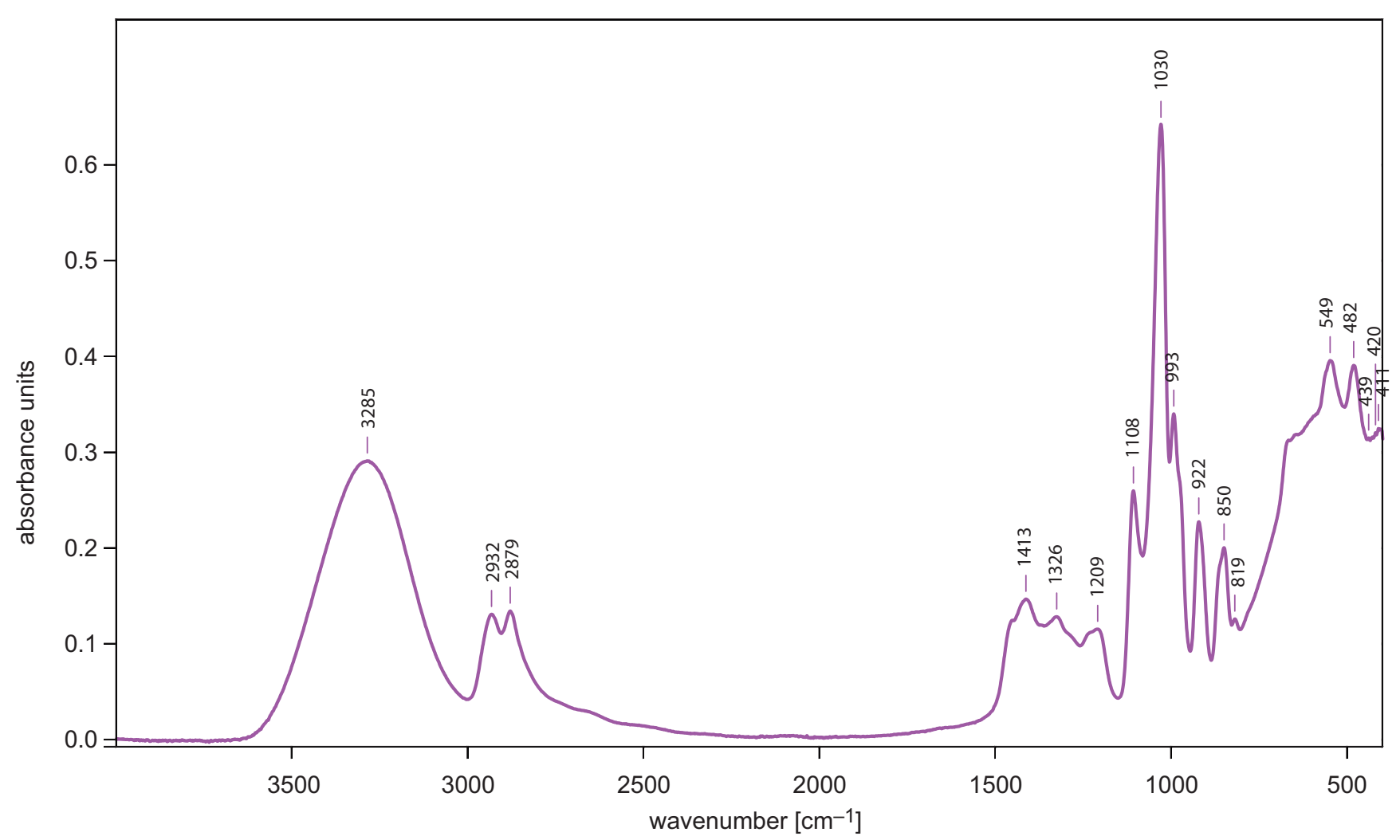

Fig. 2. A representative oscillation spectrum for a selected sample of the self-developed mixture

We compared all the samples looking for differences in the oscillatory spectra (Fig. 2). Such differences would indicate the formation of a new compound, but we did not notice any changes. The bands present in the reference sample, which contained only calcium phosphate, were also present in the samples under analysis. The marker band, which is very intense in the spectrum of $\left(\mathrm{PO}_{4}\right)_{2}$, at $963 \mathrm{~cm}^{-1}$, was present in each sample, which may indicate that no new compound had been formed. If a new form of phosphate had been formed, the marker band would have been absent. According to the literature, in Raman spectra of pure calcium phosphate (V), 4 bands (for different types of vibration symmetry) should be present: 2 bands of anion stretching vibrations $\left[\mathrm{PO}_{4}\right]^{3-}\left(v\left[\mathrm{PO}_{4}\right]^{3-}\right)$ and 2 bands that correspond to bending vibrations, i.e., $\delta\left[\mathrm{PO}_{4}\right]^{3-} \cdot{ }^{30}$ Theoretically, these bands occur at appropriate frequencies:

$-v_{1}\left[\mathrm{PO}_{4}\right]^{3-} \rightarrow 938 \mathrm{~cm}^{-1}$ (type A symmetry),

$-v_{3}\left[\mathrm{PO}_{4}\right]^{3-} \rightarrow 1017 \mathrm{~cm}^{-1}$ (type T symmetry),

$-\delta_{2}\left[\mathrm{PO}_{4}\right]^{3-} \rightarrow 420 \mathrm{~cm}^{-1}$ (type E symmetry), and

$-\delta_{4}\left[\mathrm{PO}_{4}\right]^{3-} \rightarrow 567 \mathrm{~cm}^{-1}$ (type $\mathrm{T}$ symmetry).

They correspond to the wave numbers on the infrared calcium phosphate (V) spectra (FTIR):

$-v_{1}=962 \mathrm{~cm}^{-1}$,

$-v_{3}=1024 \mathrm{~cm}^{-1}$,

$-\delta_{2}=472 \mathrm{~cm}^{-1}$, and

$-\delta_{4}=600+561 \mathrm{~cm}^{-1}$.

The same bands are observed in Raman spectra:

- $v_{1}=963 \mathrm{~cm}^{-1}$ (the most important characteristic band, the very intense marker band), $-v_{3}=1017+1048+1030 \mathrm{~cm}^{-1}$ (mean of 3 bands, fission caused by the solid effect),

- $\delta_{2}=470+432 \mathrm{~cm}^{-1}$ (mean of 2 bands), and

$-\delta_{4}=609+592+581 \mathrm{~cm}^{-1}$ (mean of 3 bands).

Based on the above, the most promising mixture was selected for further study; it showed a similar amount of glycerol and calcium phosphate (V). The intensity of the bands was similar (e.g., the intensity of the band at $1055 \mathrm{~cm}^{-1}$ from glycerol vibrations was similar to the intensity of the band at $963 \mathrm{~cm}^{-1}$ ). A small addition of citric acid was also observed in this sample (band at $1626 \mathrm{~cm}^{-1}$, vibrations in the dilution of $-\mathrm{COOH}$ citric acid groups).

\section{SEM analysis}

The SEM examinations did not show any pathological changes in the discs we evaluated. Their surfaces with open tubules, after removing the smear layer, are shown in Fig. 3. The image of the surface has been magnified $\times 1000, \times 2000$ and $\times 5000$. The dentinal tubule diameters were measured at $\times 5000$ magnification, and they ranged from $2.714 \mu \mathrm{m}$ to $3.729 \mu \mathrm{m}$ (Fig. 3D).

\section{After application of the desensitizers}

Isodan ${ }^{\circledR}$ was evenly spread across the surface of the dentin. Irregularly shaped particles (sized 4-10 $\mu \mathrm{m}$ ) were found, which were probably crystallized potassium salts, 

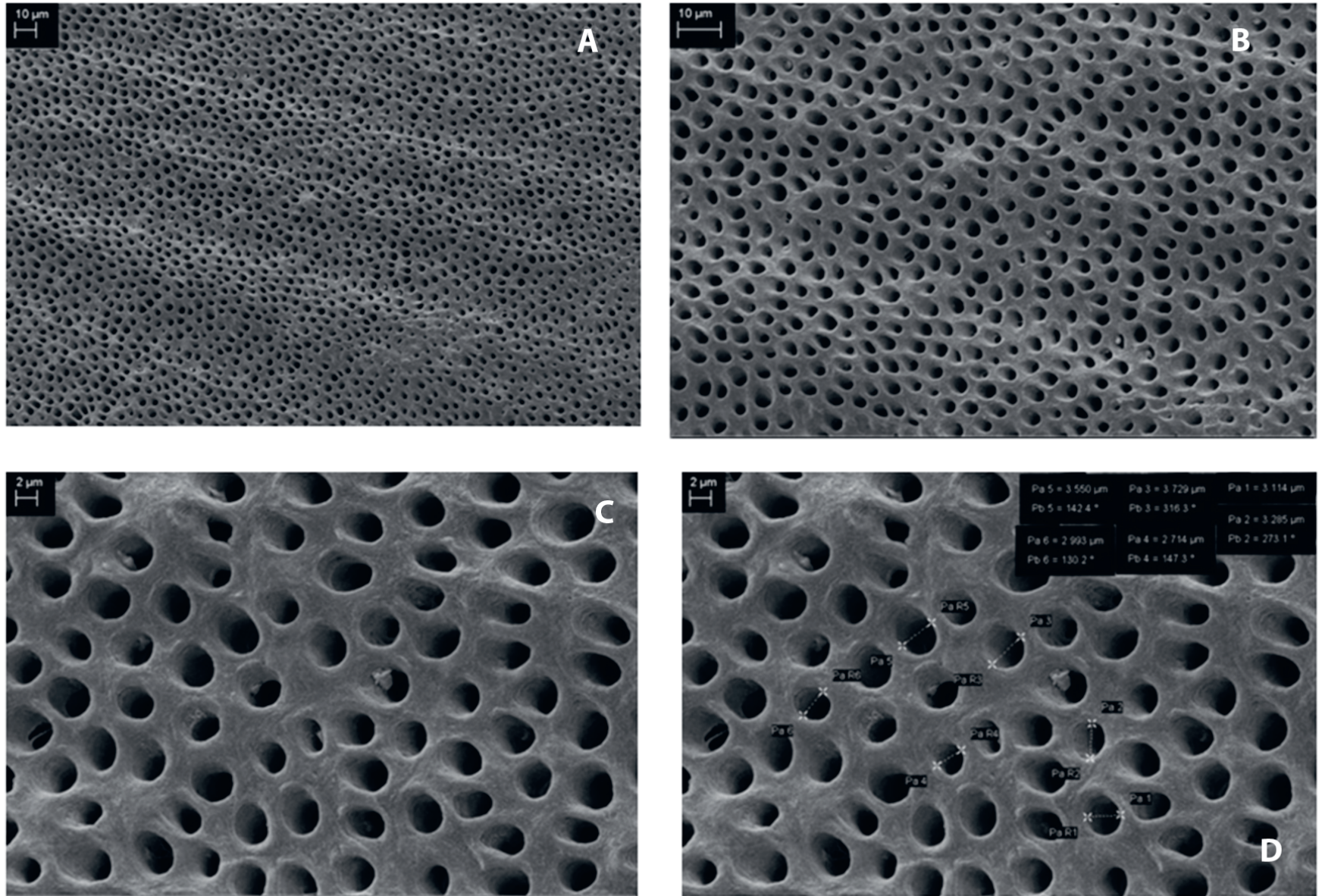

Fig. 3. SEM images of the dentin surface. A - Isodan ${ }^{\circledR}$, SEM magnification $\times 1000 ; B-H A p$, SEM magnification $\times 2000 ; C-$ Bifluorid $^{\circledR}$, SEM magnification $\times 5000$; $D-$ Cervite $^{\circledR}$, SEM magnification $\times 5000$, showing the sizes of the tubules obtained with morphometric analysis

one of the ingredients of the material (Fig. 4A). The HApbased composition developed by the authors tightly covered the dentin tubules with particles of unconnected hydroxyapatite with a maximum size of $30 \mu \mathrm{m}$ (Fig. 4B) and small crystals (sized $200 \mathrm{~nm}$ ) obliterating the tubules. Bifluorid $^{\circledR}$ created a tight, undulating layer on the dentin surface (Fig. 4C), whereas Cervitec ${ }^{\circledR}$ formed a tight varnish-like layer (Fig. 4D).

\section{After 24 hours}

On the dentin surface covered with Isodan ${ }^{\circledR}$ and incubated for $24 \mathrm{~h}$ in artificial saliva (Fig. 4), crystals of the ingredients of the desensitizer were visible. Still, they showed indications of solvency, such as blurred edges and melting. The layer covering the tubules was still present, and in comparison with the image taken just after its application (in which single tubules were open), much larger areas with still-open tubules could be seen. After examining the surface covered with HAp after a 24-hour incubation in artificial saliva (Fig. 4F), larger hydroxyapatite crystals had become smaller, and the number of smaller crystals directly blocking the tubules increased. No layer covering the dentin was observed in contrast with the previous examination, presented in Fig. 4B. After
$24 \mathrm{~h}$, Bifluorid ${ }^{\circledR}$ still covered only some areas of the surface, revealing a number of dentinal tubules (Fig. 4G). It could not be ascertained unequivocally whether the cracks present resulted from the solubility of the layer or from procedures connected with imaging. Since Bifluorid ${ }^{\circledR}$ is a varnish, the ingredients probably cracked after covering the surface and in contact with saliva, and a layer of the product probably peeled off the dentin surface. The surface covered with Cervitec ${ }^{\circledR}$ (Fig. 4H) was comparable to the image taken just after its application. The crater-like artifacts present in the image probably resulted from the process of preparing the sample for the SEM examination.

After these images were taken, the specimens were again immersed in the artificial saliva solution.

\section{After 48 hours}

After a 48-hour incubation in the artificial saliva solution, there was no trace of Isodan ${ }^{\circledR}$ on the surface (Fig. 4I). Probably, the layer dissolved and desorbed from the surface, causing the dentinal tubules to open. Also, single crystal-like formations appeared, but they may have been contaminants of the saliva solution. After $48 \mathrm{~h}$ in the artificial saliva solution, the surface covered with hydroxyapatite 

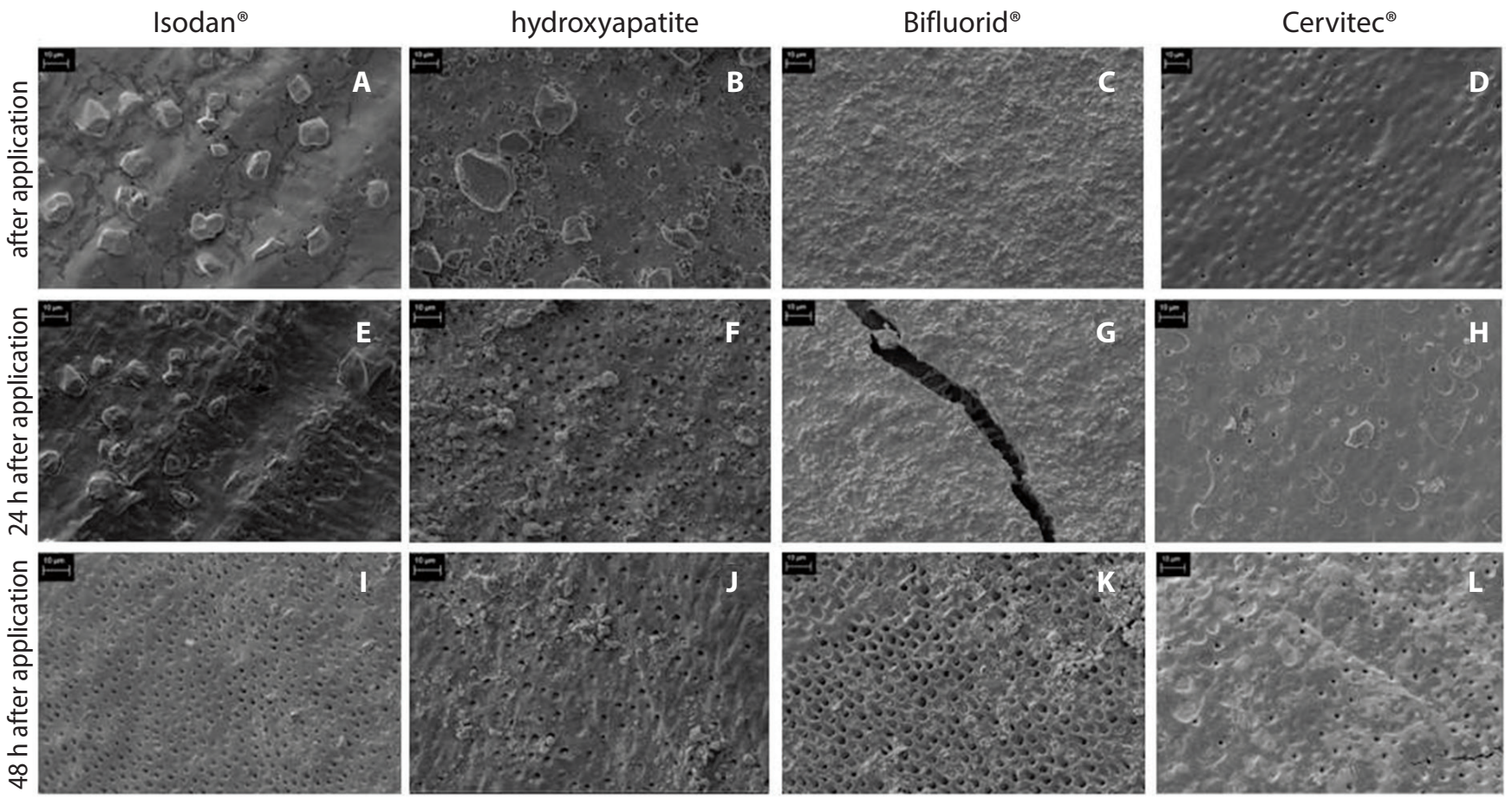

Fig. 4. Surface morphology of dentin specimens after treatment with commercial desensitizing agents (Isodan, Bifluorid, Cervitec: A/C/D) and nanohydroxyapatite (B); after $24 \mathrm{~h}(\mathrm{E}-\mathrm{H})$ and $48 \mathrm{~h}(\mathrm{I}-\mathrm{L})$ of immersion in artificial saliva. Dental specimens covered with the examined substances after drying (A-D); the different textures and sizes of crystallized compounds predominant in each desensitizer are visible. The surfaces of the discs covered with the desensitizing agents after $24 \mathrm{~h}$ of incubation in artificial saliva $(\mathrm{E}, \mathrm{H})$. The rinse-off process from the tooth surfaces; opening of the dentinal tubules can be seen. The SEM images of the dentin surfaces $48 \mathrm{~h}$ after the application of the desensitizing agents (I-L)

(Fig. 4J) still showed hydroxyapatite crystals (sized approx. $1 \mu \mathrm{m})$, creating conglomerates with uneven distribution. Also, dentinal tubules obliterated with small crystals were seen, as well as the layer covering the dentin. Examination of the surface covered with Bifluorid ${ }^{\circledR}$ after $48 \mathrm{~h}$ (Fig. 4K) revealed evident disintegration of the coating, covering the dentin with cracks, and areas with open dentinal tubules were visible. Under microscopic evaluation, dentinal tubules obliterated with particles or crystals formed from the disintegrating layer were seen. The surface covered with Cervitec ${ }^{\circledR}$ (Fig. 4L) showed single cracks and a larger number of open dentinal tubules in comparison with the previous images (Fig. 4D,H).

\section{After 7 days}

After a seven-day incubation in artificial saliva, we performed an SEM examination only for the HAp-based composition. It was impossible to do the same with the remaining desensitizers, as the layers were completely dissolved. In the sample we examined, both large and small hydroxyapatite crystals and a coating covering the dentinal surface with many cracks were observed. There were many open dentinal tubules, but also quite a large number of obliterated ones. A SEM image magnified $\times 15,000$ was taken, in which hydroxyapatite crystals obliterating dentinal tubules could be seen, as well as the layer covering the dentin around the tubules (Fig. 5).

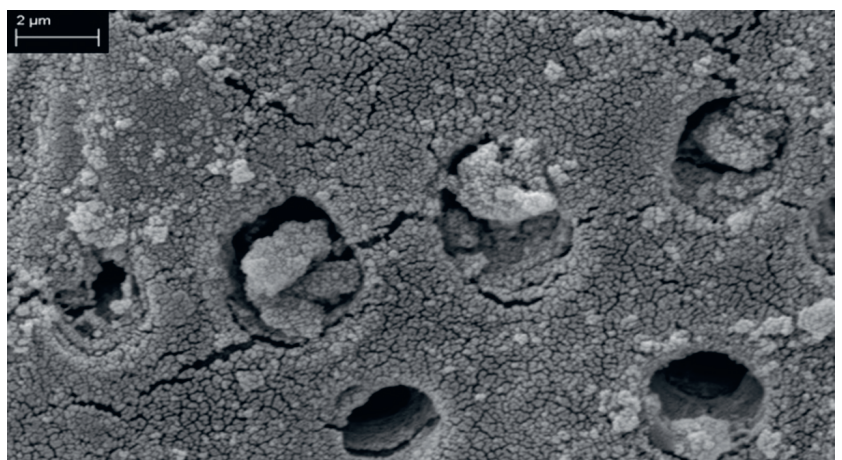

Fig. 5. The image of the dentinal disc after applying self-developed HAp-based composition and incubation in artificial saliva for 7 days. The nanoparticles constituting the composition filled dentinal tubules and effectively blocked tubular fluid flow (SEM, magnification × 15,000)

\section{Analysis of the dynamics of changes in the desensitizers}

The analysis of the dynamics of changes aimed to determine the effectiveness of closing the open dentin tubules depending on the type of desensitizer used over time (Table 1). We observed that Bifluorid ${ }^{\circledR}$, despite achieving the best results immediately after application, was characterized by very dynamic degradation at subsequent stages of observation, indicating its average durability. Cervitec ${ }^{\circledR}$ showed good results immediately after application and 
Table 1. The dynamics of changes in the number of open dentin tubules over time

\begin{tabular}{|c|c|c|c|c|c|c|}
\hline Tested agent & After application & $\begin{array}{c}24 \mathrm{~h} \text { after } \\
\text { application }\end{array}$ & $\begin{array}{c}48 \mathrm{~h} \text { after } \\
\text { application }\end{array}$ & $\begin{array}{l}168 \mathrm{~h} \text { after } \\
\text { application }\end{array}$ & Initial & Dynamics \\
\hline Bifluorid $^{\circledR}$ & 0.00 & $\infty \% \uparrow$ & $362 \% \uparrow$ & no data & ++ & -- \\
\hline Cervitec $^{\mathbb{R}}$ & 45.00 & $20 \% \downarrow$ & $64 \% \uparrow$ & no data & $+/-$ & $+/-$ \\
\hline HAp & 4.00 & $1050 \% \uparrow$ & $67 \% \downarrow$ & $7 \% \downarrow$ & + & + \\
\hline Isodan ${ }^{\circledR}$ & 0.00 & $17.00 \% \downarrow$ & no data & no data & + & -- \\
\hline
\end{tabular}
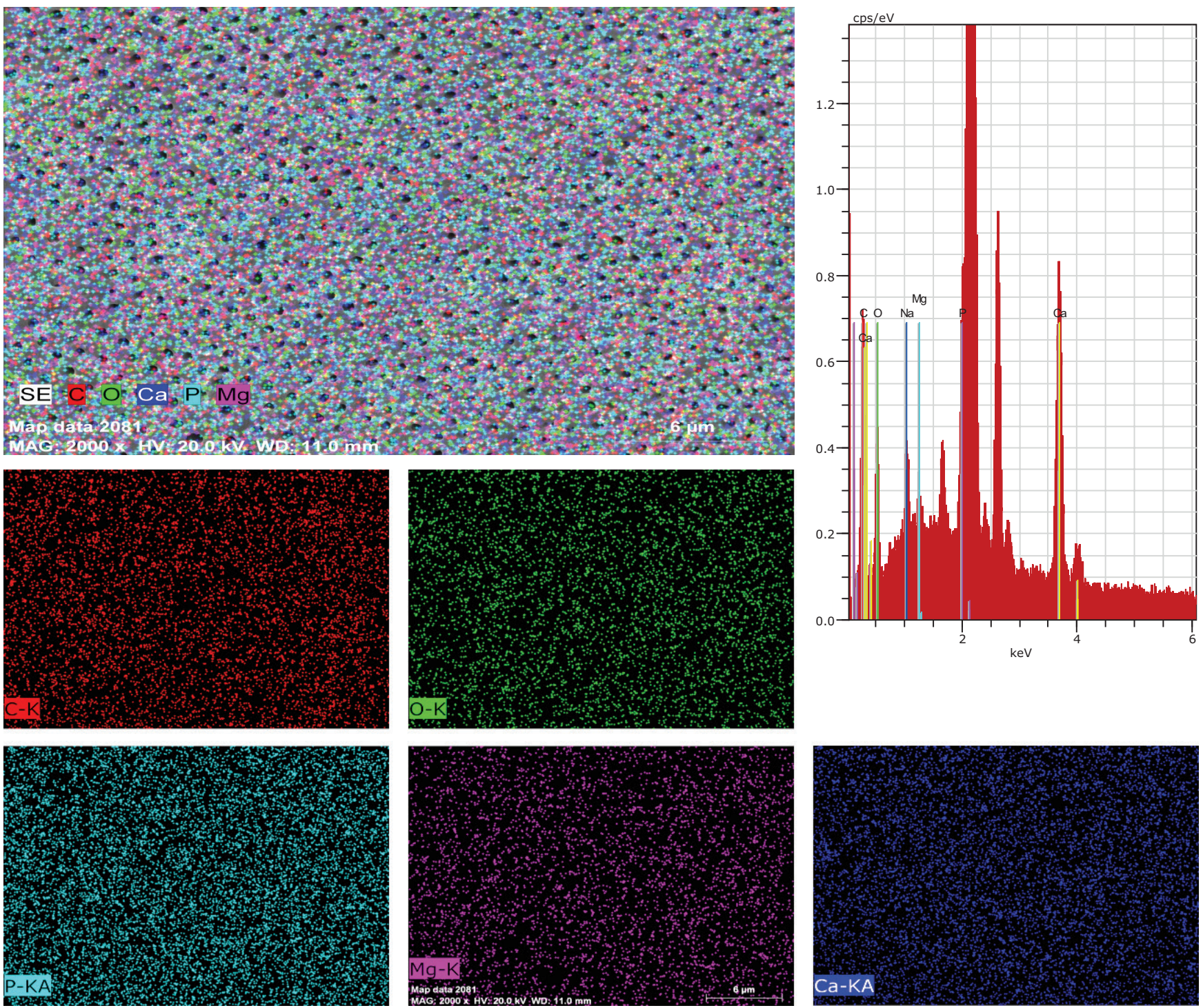

Fig. 6. Surface mapping of the reference sample with a chemical composition graph. Chemical analyses of the 4 surfaces after application of the tested preparations showed the presence of characteristic elements for the given agent. For Isodan ${ }^{\circledR}$, it was potassium and fluorine; for the self-developed desensitizer, calcium and phosphorus; for Bifluorid ${ }^{\circledR}$ it was fluorine; and for Cervitec ${ }^{\mathbb{B}}$, chlorine. Also see Fig. 7 and 8

a very slow degradation rate at subsequent stages of observation, which indicated its relatively higher effectiveness. Our hydroxyapatite-based agent, despite its initially limited effectiveness, was the only substance showing gradation at successive time stages. In other words, its effectiveness only appeared some time after the compound was deposited on the surface of the tooth. This shows its superiority over the other agents, in which the quality of tooth protection weakened with time. Isodan ${ }^{\circledR}$ exhibited moderate efficacy when the first measurement was performed and significant (almost total) degradation with subsequent analyses. These results allowed us to draw very cautious conclusion that, in terms of the stability of the effects of the applied tubular obliteration technique, the best results can be obtained with the use of a hydroxyapatitebased formulation with apatite crystals sized $\leq 300 \mathrm{~nm}$. 


\section{Results of the chemical analyses of the tested surfaces}

After performing the chemical analyses and surface mapping of the reference sample, the presence of elements such as carbon, oxygen, calcium, phosphorus, and magnesium characteristic of the dentin surface imaged using the SEM technique was revealed (Fig. 6).

Figure 7 presents the dynamics of the changes in the concentration of elements over time ( 0 h, 24 h, 48 h, 168 h) for all the tested agents. Since the protective layer created by Isodan ${ }^{\circledR}$ dissolved completely within $48 \mathrm{~h}$, it was excluded from further analysis. At hour 168, only the self-developed pharmaceutical composition was analyzed because it was the only agent still present on the dentin surface. The cumulative chart presents 4 samples (B, C, H, I) with selected elements. The bars on the graph do not represent the entire chemical composition, but only quantitative contents of the selected compounds (Fig. 8).

The chemical analysis of Isodan ${ }^{\circledR}$ performed immediately after its application showed the presence of elements such as potassium and sodium, as well as fluorine and nitrogen, most likely derived from the potassium nitrate and calcium fluoride present in the formulation (Fig. 7A). The hydroxyapatite-based desensitizer showed the presence of $2.26 \%$ phosphorus and $1.17 \%$ calcium in a molar ratio similar to the reference sample (Fig. 7B). The surface covered with the $3^{\text {rd }}$ desensitizer $\left(\right.$ Bifluorid $^{\circledR}$ ) showed significant amounts of fluorine, representing $47.52 \%$ of the chemical composition of the whole surface (Fig. 7C). The percentage increase in calcium content and the significant amounts of fluoride are most likely derived from calcium fluoride, which is the main component of Bifluorid ${ }^{\circledR}$. In the chemical analysis of Cervitec ${ }^{\circledR}$ (Fig. 7D), the presence of chlorine was observed, most likely derived from chlorhexidine acetate, the main active ingredient of the product.

After $24 \mathrm{~h}$ of immersion in the artificial saliva solution, another chemical analysis of the surfaces was performed. In the case of Isodan ${ }^{\circledR}$, an absence of fluorine and potassium (present in the first image) and unchanged levels of nitrogen and sodium were observed (Fig. 7E). The chemical composition of the HAp-based substance had not changed, but the ratio of phosphate ions to calcium ions was different (Fig. 7F) with an increase in phosphate ions. The chemical analysis of Bifluorid ${ }^{\circledR}$ revealed 1.5 times greater concentrations of calcium and phosphorus, and a ten-fold increase in fluorine (Fig. 7G) compared to the analysis immediately after application. This may indicate the release of these ions under the influence of saliva. The analysis of Cervitec ${ }^{\circledR}$ (Fig. 7H) showed that chlorine ions were still present (3 times fewer of them compared to the sample analyzed immediately after application).

After $48 \mathrm{~h}$ of immersion (Fig. 7J), the quantity of calcium and phosphorus ions in the HAp-based product was 4 times higher than in the earlier samples. This may indicate that artificial saliva influenced the dissolution of hydroxyapatite crystals and caused a steady release of calcium and phosphorus. Fluorine ions were still present on the Bifluorid ${ }^{\circledR}$ treated surface (Fig. $7 \mathrm{~K}$ ); however, compared to the $1^{\text {st }}$ measurements, their quantity had decreased by $1 / 3$. A significant decrease in the concentration of phosphorus and calcium ions was also observed. For Cervitec ${ }^{\circledR}$ (Fig. 7L), minimal levels of calcium, phosphate and chloride ions were found. Chemical analysis of the HA-p-based desensitizer made 7 days after immersion in the artificial saliva solution showed the presence of calcium and phosphate ions in a molar ratio of about 1: 1, similarly to the test performed after $24 \mathrm{~h}$ (Fig. 9).

\section{Statistical analysis}

The study showed an empirical average of observed tubular diameters of $3.01 \mu \mathrm{m}$, with a minimum of $2.18 \mu \mathrm{m}$ and a maximum of $4.30 \mu \mathrm{m}$. We tested the null hypothesis that the size of dentin tubules was $\geq 3 \mu \mathrm{m}$, with $\mathrm{p}>0.9$ (Table 2). Thus, the results of the statistical analysis confirm that as objects with diameters not exceeding $2.00 \mu \mathrm{m}$, hydroxyapatite crystals used as the active substance can penetrate defects occurring in the tooth surface and block tubular light.

Table 2. Sizes of the dentin tubules (where $\sigma$ is standard deviation, and $\mathrm{H}$ is the null hypothesis)

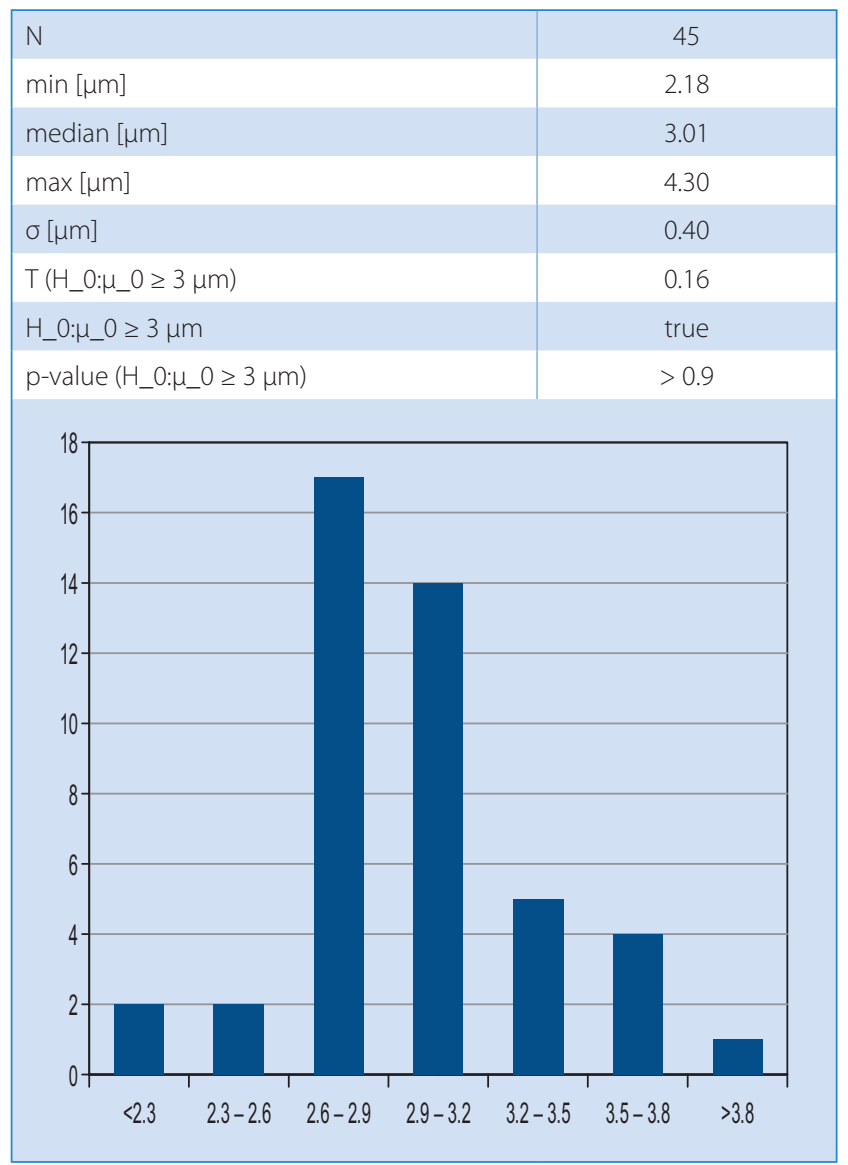



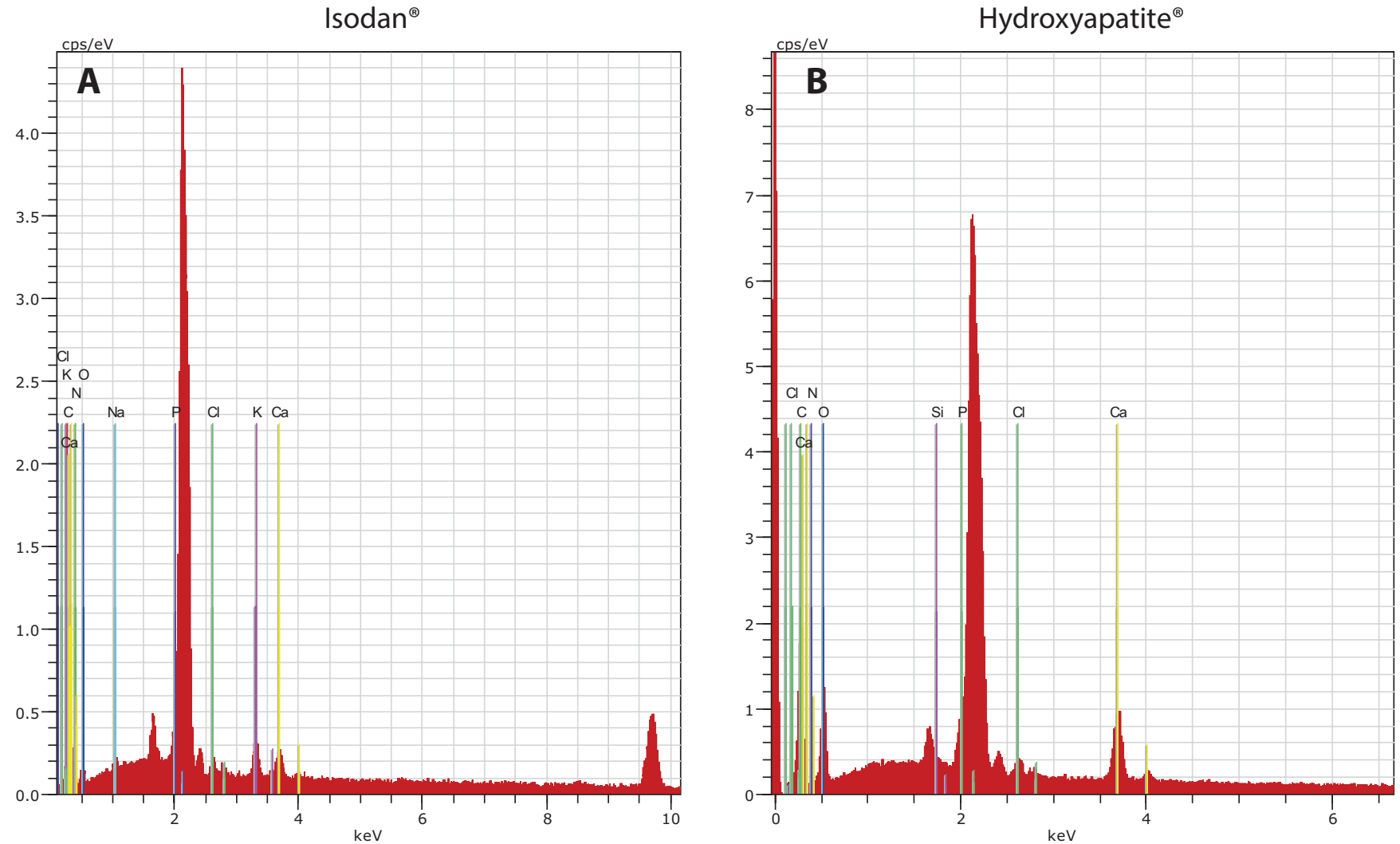

Bifluorid $^{\circledast}$
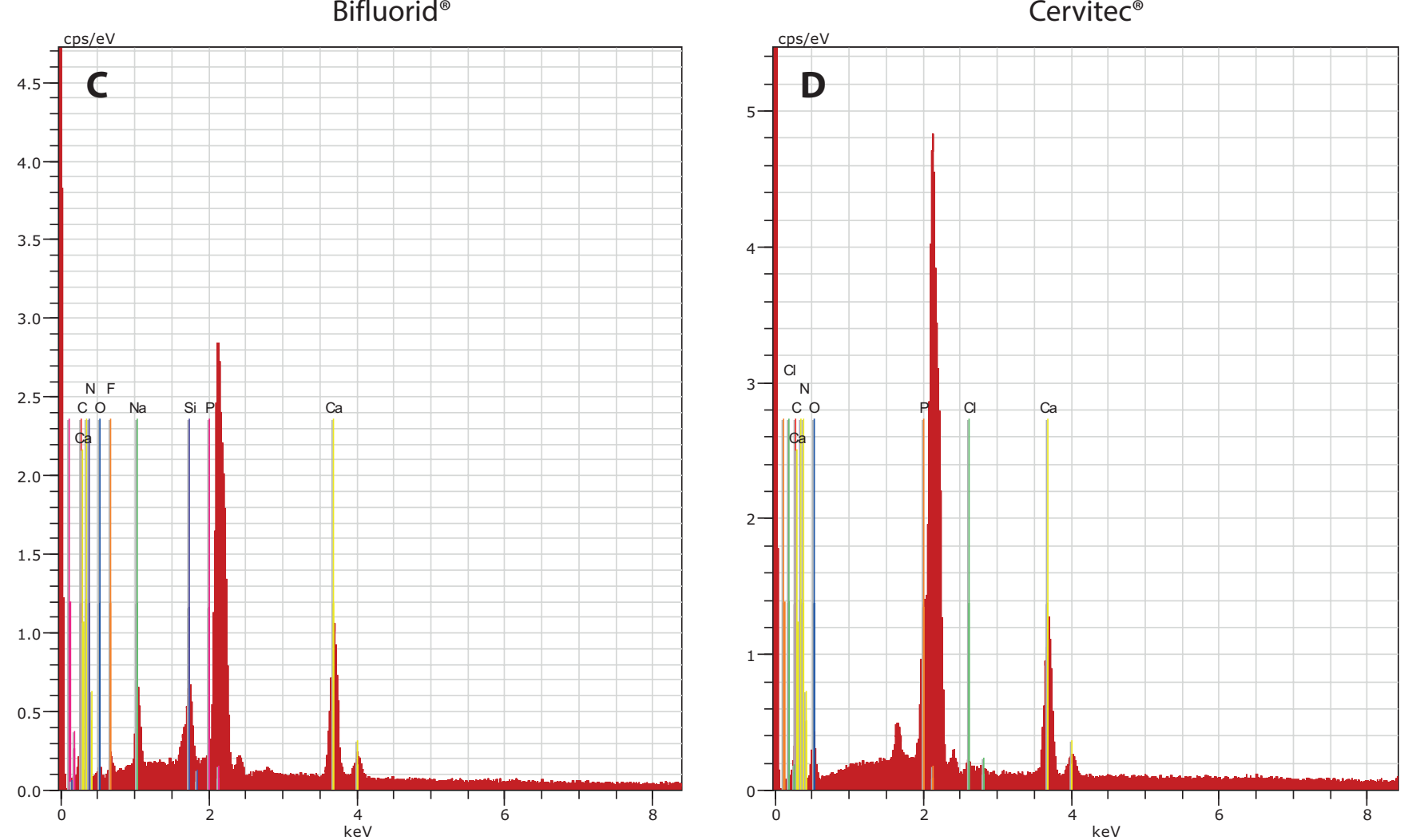

Fig. 7A-D. Chemical analysis of the surfaces with the agents applied. Chemical structure of the specimens just after application 

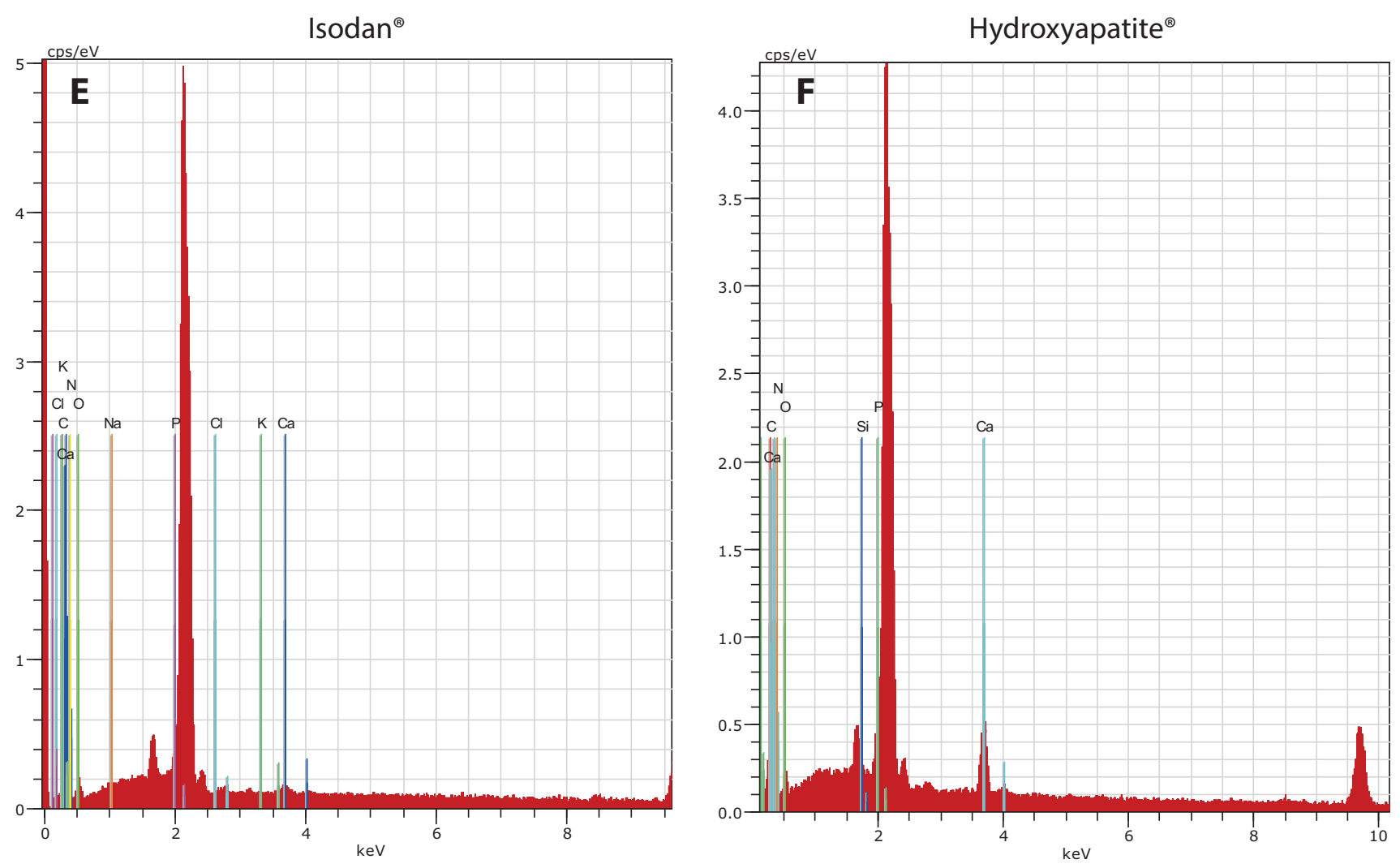

Bifluorid $^{\circledR}$
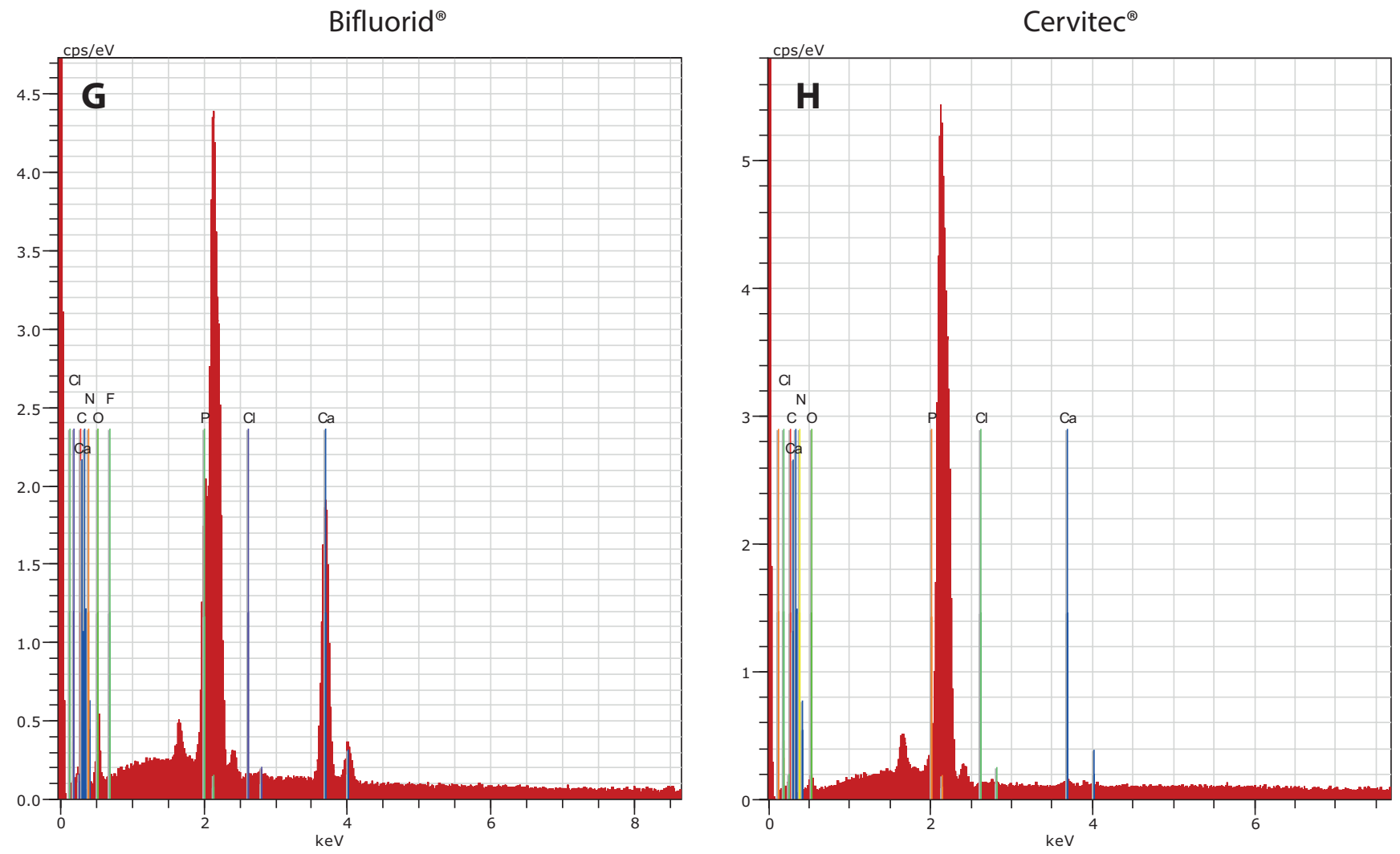

Fig. 7E-H. Chemical analysis of the surfaces with the agents applied. After a $24 \mathrm{~h}$ of immersion in artificial saliva 

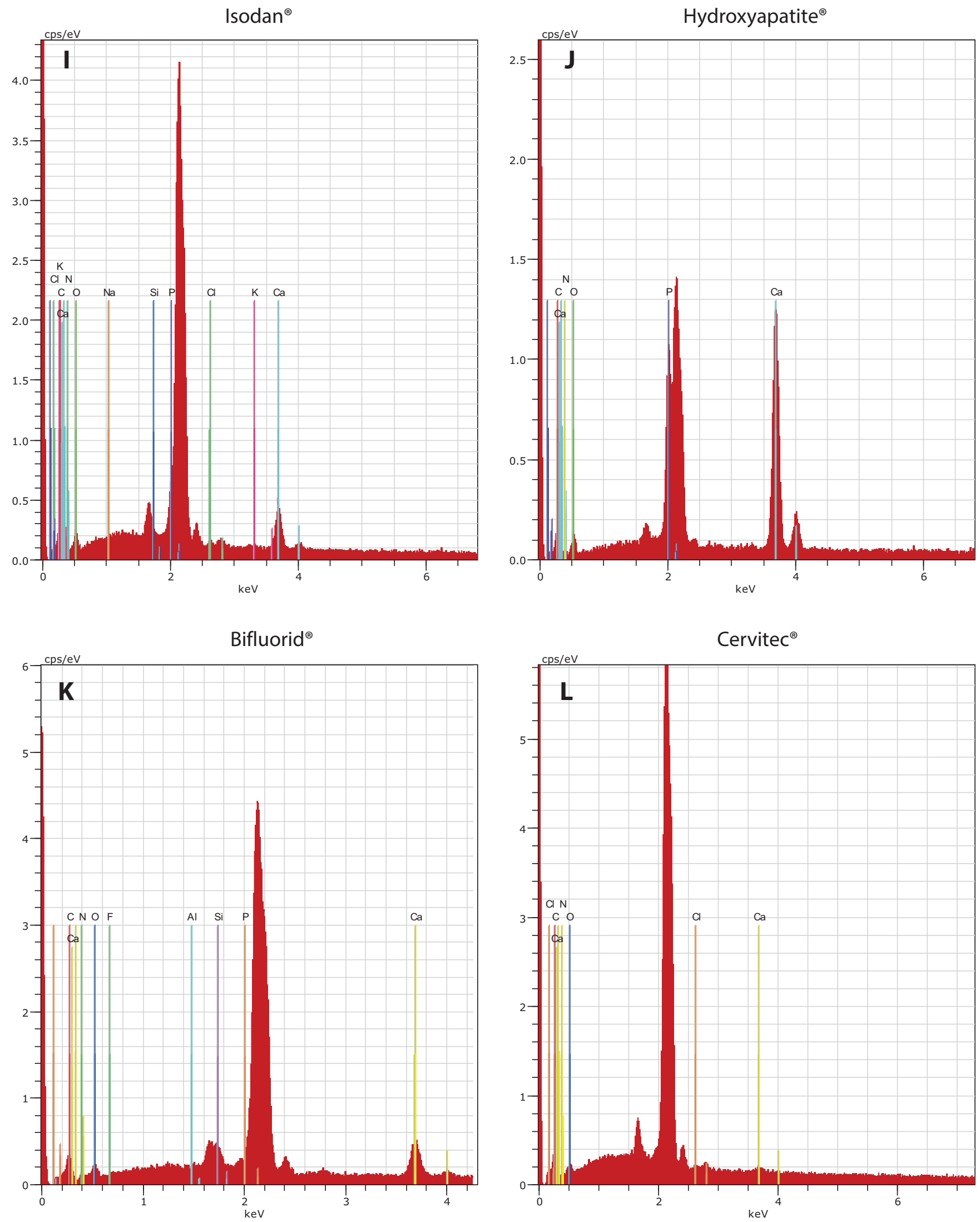

Fig. 7l-L. Chemical analysis of the surfaces with the agents applied. After $48 \mathrm{~h}$ of immersed in artificial saliva 


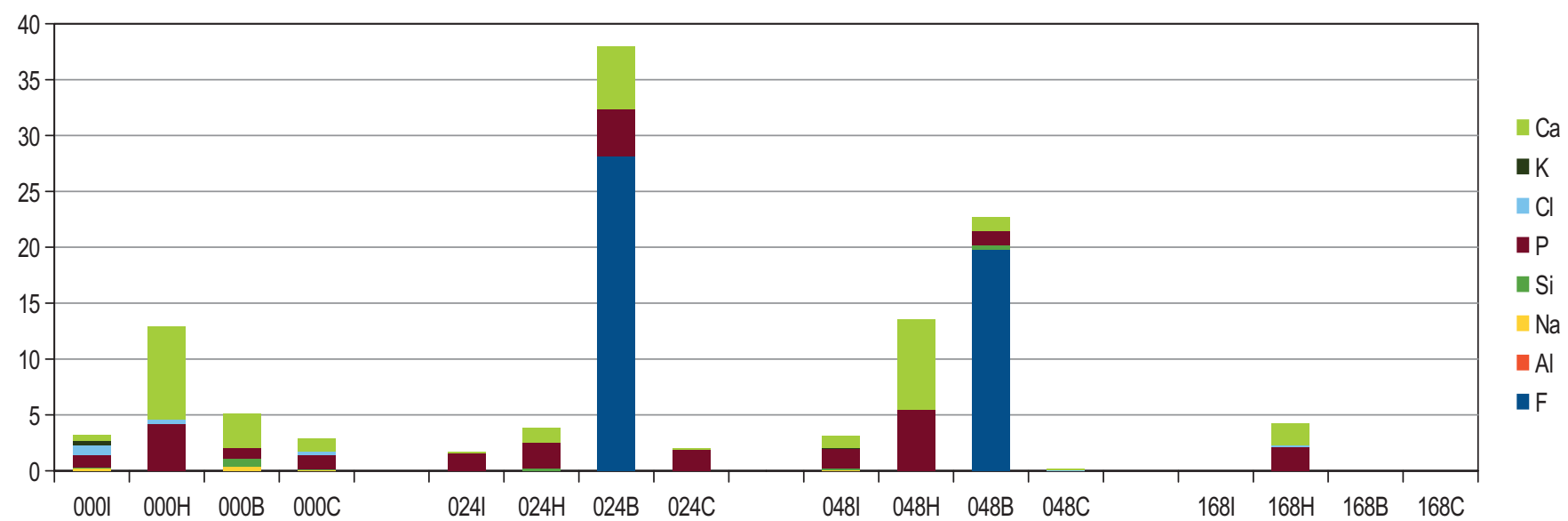

Fig. 8. Dynamics of change in the concentration of chemical elements over time (B - Bifluorid ${ }^{\circledR} ; C-$ Cervitec $^{\circledR} ; I-I \operatorname{sodan}^{\circledR} ; H$ - hydroxyapatite)

\section{Discussion}

Tubule occlusion can be brought about by the deposition of mineral crystals either on the surface and/or within the dentinal tubules. Superficial occlusion of tubules can provide only short-term relief as the precipitate can either be removed by daily tooth brushing or dissolved by saliva and/or consumption of acidic beverages. Effective treatment with long-term results has been related to intratubular deposition of mineral crystals. ${ }^{31,32}$

Treatment of DH focuses on using substances that limit dentin permeability by obliterating dentinal tubules, making the dentin insensitive to stimuli like airflow or probing, which, in normal conditions, cause dentinal fluid flow, and as a consequence activate the nerve endings present, inflicting pain. ${ }^{33}$ Studies have shown that dentinal fluid flow is proportional to the $4^{\text {th }}$ power of the tubule radius. This means that when we reduce the radius by half anywhere along its length, the fluid flow will not decrease by half but to the $4^{\text {th }}$ power, i.e., to $1 / 16$ of its primary flow. ${ }^{34}$ On the basis of the above, it may be concluded that to reduce or eliminate $\mathrm{DH}$, it is not necessary to occlude tubules completely; but at the same time, the question arises what extent of obliteration is sufficient and what percentage of exposed tubules should be obliterated to reduce DH so that the patient feels relief. Different active ingredients have been studied to assess their ability to treat DH. The commercially available desensitizing agents used in the present study consisted of such active ingredients as potassium nitrate, sodium fluoride, calcium fluoride, and chlorhexidine. McCornack and Davies suggested that potassium nitrate stimulates odontoblasts to synthesize and secrete nitric oxide (NO), which may act as a nerve blocker. ${ }^{34}$ Moreover, it has been observed that in the right concentration, potassium salts (e.g., potassium chloride) are able to block the activity of the tubular nerve endings. ${ }^{33}$ Calcium salts and phosphate-containing substances are supposed to generate the deposition of amorphous calcium phosphate crystals in the openings, while acidic calcium phosphate forms precipitates inside the dentinal tubules. ${ }^{35}$ Fluorine ions may react with free calcium ions and form calcium fluoride aggregates by occluding dentinal tubules. ${ }^{36}$ Ten Cate observed that a very low concentration of fluorine in liquid form at a low $\mathrm{pH}$ could almost completely block the dissolution of apatite crystals and reduce the degree of demineralization. ${ }^{37}$ Bizhang et al. reported that chlorhexidine (which inhibits the growth of bacteria permanently present on the tooth surface) protects teeth against demineralization. ${ }^{38}$ Also, satisfactory effects were obtained by combining chlorhexidine with fluoride. ${ }^{39}$ Madruga et al. compared the desensitizing efficacy of the resin-modified glass ionomer cement (GIC) Clinpro $^{\mathrm{TM}}$ XT (3M ESPE) and the conventional GIC Vidrion R (SS White Group, Gloucester, UK). Their findings suggest that conventional and resin-modified glass ionomer cements are also successful in managing $\mathrm{DH} .{ }^{40}$

Dentin adhesion is not as easily achieved as enamel adhesion, since dentin is living tissue and enamel is not. The undisturbed permeability of the dentinal fluid from the chamber to the outside while preparing dentin causes its surface to undergo constant changes. In addition, all the agents applied to dentin and enamel surfaces are dissolved by tubular fluid. The smear layer on a prepared tooth consists of particles of dentin, collagen fibers, odontoblast residue, and bacteria. Its thickness ranges from $0.5 \mu \mathrm{m}$ to $5.0 \mu \mathrm{m}$. It also prevents contact and chemical reactions with an active agent bonding with the dentin or with a desensitizing agent. ${ }^{41,42}$ This is why in order to expose the tubules and collagen fibers, it is necessary to achieve bonding of the desensitizers with the dentin, which has to undergo chemo-mechanical preparations. The HAp-based composition seems to create a layer made of larger hydroxyapatite crystals (10-20 $\mu \mathrm{m}$ in size), which may constitute a reservoir of phosphorus and calcium ions as precursors of calcium phosphate - a substrate necessary for the next stage in the dentin remineralization process. ${ }^{43-46}$ Our chemical analysis and SEM examinations demonstrated that the HAp-based composition also consists of smaller 

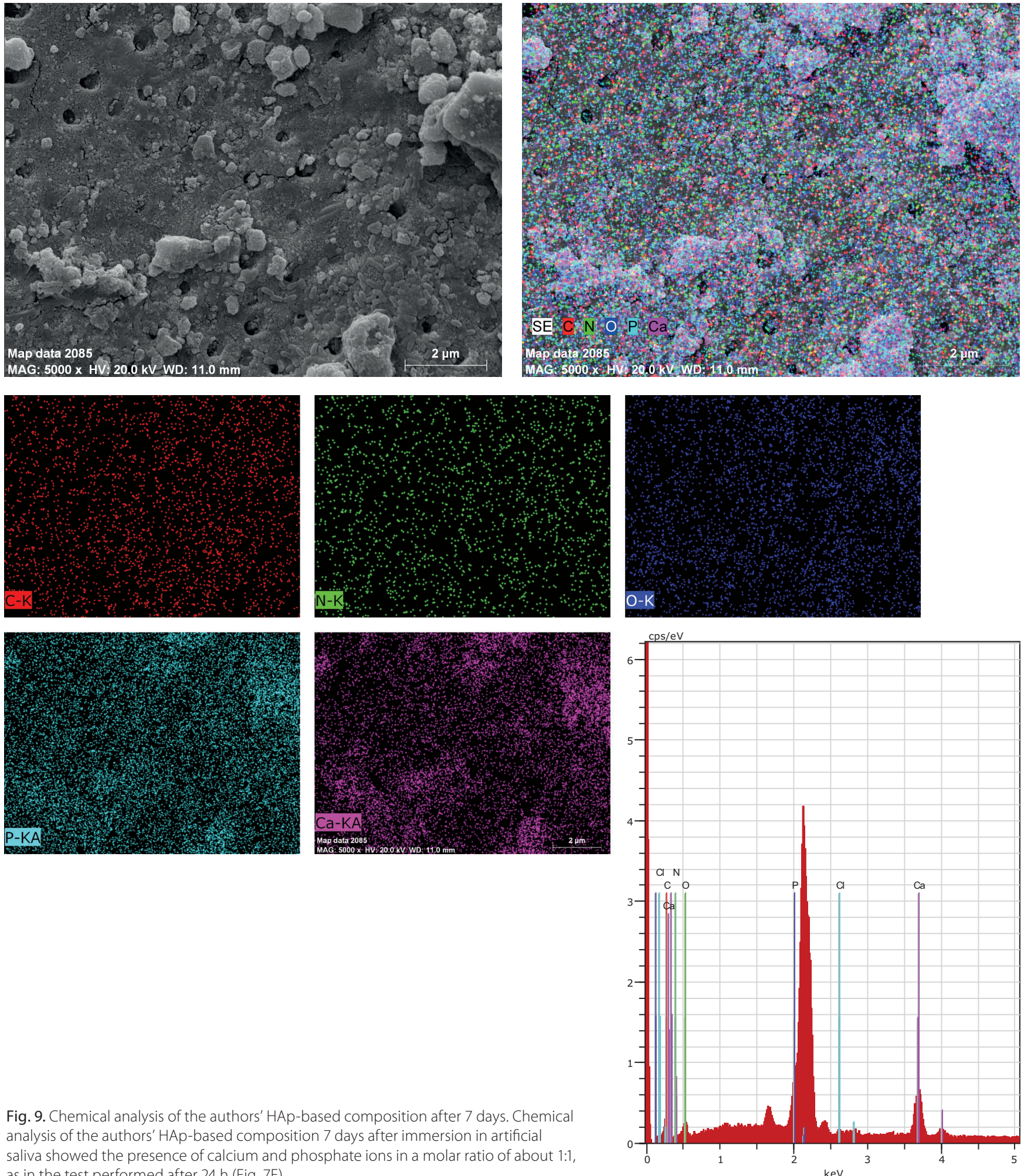

g. 9. Chemical analysis of the authors' HAp-based composition after 7 days. Chem analysis of the authors' HAp-based composition 7 days after immersion in artificial saliva showed the presence of calcium and phosphate ions in a molar ratio of about 1:1, as in the test performed after $24 \mathrm{~h}$ (Fig. 7F)

crystals $(0.2-0.3 \mu \mathrm{m})$ that successfully occlude dentinal tubules. Moreover, the layer formed seems to be durable, which has been proven by showing that both larger and smaller crystals were still present after rinsing for $24 \mathrm{~h}$, $48 \mathrm{~h}$ and 7 days in the artificial saliva solution.

The aim of the analysis was to determine the ability to close open dentin tubules depending on the type of the desensitizer used and time elapsed since its application (Table 1). The analysis of the dynamics of the number of exposed dentinal tubules showed that Bifluorid ${ }^{\circledR}$, in spite of achieving the best results immediately after application, is characterized by very dynamic degradation at subsequent stages of observation, indicating its moderate durability; Cervitec ${ }^{\circledR}$ showed good results immediately 
after application and a very slow degradation rate at subsequent stages of observation, which indicates its good quality; the HAp-based composition, despite its initially limited effectiveness, was the only substance showing a gradation at successive time stages. In other words, its effectiveness only appeared after some time, when compounds were deposited on the surface of the tooth closing the tubules. Isodan ${ }^{\circledR}$ exhibited moderate efficacy when the $1^{\text {st }}$ measurement was performed and significant (almost total) degradation with subsequent analyses. The HAp-based pharmaceutical composition consists of biocompatible and biodegradable chemical compounds that can be found in our bodies. Hence any products of its dissolution should be removed through natural metabolic processes. This composition did not change its properties during storage. These results allow us to draw very cautious conclusions that, in terms of the stability of the effects of the applied tubular obliteration technique, the best results can be obtained with the use of a hydroxyapatite-based formulation with apatite crystals sized $\leq 300 \mathrm{~nm}$.

\section{Conclusions}

This in vitro study has shown that the use of hydroxyapatite particles $<300 \mathrm{~nm}$ suspended in glycerol allows effective obliteration of dentinal tubules, which was shown in SEM images. It has been demonstrated that the use of a HAp-based agent with crystals smaller than $300 \mathrm{~nm}$ may occlude dentinal tubules, making it useful in the treatment and prevention of $\mathrm{DH}$. In the given experimental conditions, the durability of the protective coating after applying the authors' own pharmaceutical composition was greater than all the other tested desensitizers. ${ }^{47}$ This makes it an excellent alternative to pharmaceutical products based on fluoride, potassium nitrate or multi-component products, but further studies are required to confirm these findings.

\section{ORCID iDs}

Łukasz Rafał Pałka (1) https://orcid.org/0000-0002-9365-7882 Zbigniew Rybak (1) https://orcid.org/0000-0002-1906-6435 Piotr Kuropka (1) https://orcid.org/0000-0002-0682-4743

Maria Krystyna Szymonowicz (1) https://orcid.org/0000-0003-4251-6841 Jan Kiryk (10 https://orcid.org/0000-0002-5442-1412

Krzysztof Marycz (10 https://orcid.org/0000-0003-3676-796X

Maciej Dobrzyński (1) https://orcid.org/0000-0003-2368-1534

\section{References}

1. Farooq I, Moheet IA, AI-Shwaimi E. In vitro dentin tubule occlusion and remineralization competence of various toothpastes. Arch Oral Biol.2015;60(9):1246-1253. https://doi.org/10.1016/j.archoral bio.2015.05.012

2. Gillam DG. Current diagnosis of dentin hypersensitivity in the dental office: An overview. Clin Oral Investig. 2013;17(Suppl 1):S21-S29. https://doi.org/10.1007/s00784-012-0911-1

3. Saeki K, Marshall GW, Gansky SA, Parkinson CR, Marshall SJ. Strontium effects on root dentin tubule occlusion and nanomechanical properties. Dent Mater. 2016;32(2):240-251. https://doi.org/10.1016/j. dental.2015.11.020
4. Brännström M. Sensitivity of dentin. Oral Surg Oral Med Oral Pathol. 1966;21(4):517-526. https://doi.org/10.1016/0030-4220(66)90411-7

5. Brännström M, Garberoglio R. The dentinal tubules and the odontoblast processes: A scanning electron microscopic study. Acta Odontol Scand. 1972;30(3):291-311. https://doi.org/10.3109/00016 357209004598

6. Cakar G, Kuru B, Ipci SD, Aksoy ZM, Okar I, Yilmaz S. Effect of Er:YAG and $\mathrm{CO}_{2}$ lasers with and without sodium fluoride gel on dentinal tubules: A scanning electron microscope examination. Photomed LaserSurg. 2008;26(6):565-571. https://doi.org/10.1089/pho.2007.2211

7. Miglani S, Aggarwal V, Ahuja B. Dentin hypersensitivity: Recent trends in management. J Conserv Dent. 2010; 13(4):218-224. https://doi.org/ 10.4103/0972-0707.73385

8. Poulsen S, Errboe M, Lescay Mevil Y, Glenny AM. Potassium containing toothpastes for dentin hypersensitivity. Cochrane Database Syst Rev. 2006;2006(3):CD001476. https://doi.org/10.1002/14651858. CD001476.pub2

9. Pereira J, Sales-Peres S, Francisconi L, et al. Current and novel clinical approaches for the treatment of dentin hypersensitivity. In: Gilligan D, ed. Dentin Hypersensitivity: Advances in Diagnosis, Management, and Treatment. Cham, Switzerland: Springer International Publishing Switzerland; 2015:101-132.

10. Birang R, Poursamimi J, Gutknecht N, Lampert F, Mir M. Comparative evaluation of the effects of Nd:YAG and Er:YAG laser in dentin hypersensitivity treatment. Lasers Med Sci. 2007;22(1):21-24. https:// doi.org/10.1007/s10103-006-0412-z

11. Shetty S, Kohad R, Yeltiwar R, Shetty K. Comparative evaluation of hydroxyapatite, potassium nitrate and sodium monofluorophosphate as in office desensitising agents: A double blinded randomized controlled clinical trial. J Oral Hyg Health. 2013;1:104. doi:10.4172/ 2332-0702.1000104

12. Low $B, A$ Alen EP, Kontogiorgos ED. Reduction in dental hypersensitivity with nano-hydroxyapatite, potassium nitrate, sodium monoflurophosphate and antioxidants. Open Dent. 2015;(9):92-97. doi:10.2174/ 1874364101509010092

13. Orchardson R, Gillam DG. The efficacy of potassium salts as agents for treating dentin hypersensitivity. J Orofac Pain. 2000;14(1):9-19.

14. Orchardson R, Gillam DG. Managing dentin hypersensitivity. J Am Dent Assoc. 2006;137(7):990-998, quiz 1028-1029. doi:10.14219/jada. archive.2006.0321

15. Peacock JM, Orchardson R. Effects of potassium ions on action potential conduction in A- and C-fibers of rat spinal nerves. J Dent Res. 1995; 74(2):634-641. doi:10.1177/00220345950740020301

16. James JM, Puranik MP, Sowmya KR. Dentinal tubule occluding effect of potassium nitrate in varied forms, frequencies and duration: An in vitro SEM analysis. J Clin Diagn Res. 2017;11(8):ZC06-ZC08. doi:10.7860/JCDR/2017/26442.10340

17. Mahmoodi B, Wood RJK, Cook RB. Nanomechanical properties of hydroxyapatite like coatings formed by bioactive glasses, arginine and calcium silicate for dentin protection. JMech Behav Biomed Mater. 2020;105:103702. doi:10.1016/j.jmbbm.2020.103702

18. Rosenthal MW. Historic review of the management of tooth hypersensitivity. Dent Clin North Am. 1990;34(3):403-427.

19. Yu J, Yang H, Li K, Lei J, Zhou L, Huang C. A novel application of nanohydroxyapatite/mesoporous silica biocomposite on treating dentin hypersensitivity: An in vitro study. J Dent. 2016;50:21-29. doi:10.1016/j. jdent.2016.04.005

20. Hanni M, Hannig C. Nanomaterials in preventive dentistry. Nat Nanotechnol. 2010;5(8):565-569. doi:10.1038/nnano.2010.83

21. Ohta K, Kawamata H, Ishizaki T, Hayman R. Occlusion of dentinal tubules by nano-hydroxyapatite. J Dent Res. 2007;86(Spec Iss A): New Orleans Abstracts No. 1759.

22. Tschoppe P, Zandim DL, Martus P, Kielbassa AM. Enamel and dentin remineralization by nano-hydroxyapatite toothpastes. J Dent. 2011; 39(6):430-437. doi:10.1016/j.jdent.2011.03.008

23. Al-Maliky MA, Mahmood AS, Al-Karadaghi TS, et al. The effects of $\mathrm{CO}_{2}$ laser with or without nanohydroxyapatite paste in the occlusion of dentinal tubules. ScientificWorldJournal. 2014;2014:798732. https:// doi.org/10.1155/2014/798732

24. Onwubu SC, Mhlungu S, Mdluli PS. In vitro evaluation of nanohydroxyapatite synthesized from eggshell waste in occluding dentin tubules. J Appl Biomater Funct Mater. 2019;17(2):2280800019851764. doi:10.1177/2280800019851764 
25. Pajor K, Pajchel L, Kolmas J. Hydroxyapatite and fluorapatite in conservative dentistry and oral implantology: A review. Materials (Basel). 2019;12(17):2683. doi:10.3390/ma12172683

26. Mordan NJ, Barber PM, Gillam DG. The dentine disc. A review of its applicability as a model for the in vitro testing of dentine hypersensitivity. J Oral Rehabil. 1997;24(2):148-156. doi:10.1046/j.1365-2842.1997. d01-260.x

27. Mordan NJ, Barber PM, Gillam DG. The dentin disc: A review of its applicability as a model for the in vitro testing of dentin hypersensitivity. J Oral Rehabil. 1997;24(2):148-156. https://doi.org/10. 1046/j.1365-2842.1997.d01-260.x

28. Gillam DG, Mordan NJ, Newman HN. The dentin disc surface: A plausible model for dentin physiology and dentin sensitivity evaluation. Adv Dent Res. 1997;11(4):487-501. https://doi.org/10.1177/089593749 70110041701

29. Ling TY, Gillam DG, Barber PM, Mordan NJ, Critchell J. An investigation of potential desensitizing agents in the dentin disc model: A scanning electron microscopy study. J Oral Rehabil. 1997;24(3):191203. https://doi.org/10.1111/j.1365-2842.1997.tb00313.x

30. Nakamoto K. Infrared and Raman spectra of inorganic and coordination compounds. In: Chalmers JM, Griffiths PR, eds. Handbook of Vibrational Spectroscopy. Hoboken NJ: John Wiley \& Sons; 2006. doi:10.1002/0470027320.s4104

31. Lodish HF, Berk A, Kaiser C, et al, eds. Molecular Cell Biology. London, UK: Palgrave Macmillan; 2008

32. Suge T, Ishikawa K, Kawasaki A, Yoshiyama M, Asaoka K, Ebisu S. Effects of fluoride on the calcium phosphate precipitation method for dentinal tubule occlusion. J Dent Res. 1995;74(4):1079-1085. https://doi.org/10.1177/00220345950740040801

33. Markowitz K, Kim S. Hypersensitive teeth: Experimental studies of dentinal desensitizing agents. Dent Clin North Am. 1990;34(3):491-501.

34. McCormack K, Davies, R. The enigma of potassium ion in the management of dentin hypersensitivity: Is nitric oxide the elusive second messenger? Pain. 1998;68(1):5-11.

35. Suge T, Ishikawa K, Kawasaki A, et al. Calcium phosphate precipitation method for the treatment of dentin hypersensitivity. Am J Dent. 2002;15(4):220-226.
36. Thrash WJ, Jones DL, Dodds WJ. Effect of a fluoride solution on dentinal hypersensitivity. Am J Dent. 1992;5(6):299-302.

37. Ten Cate JM. In vitro studies on the effects of fluoride on de- and remineralization. J Dent Res. 1990;69(Spec No):614-619, discussion 634-636.

38. Bizhang M, Seemann R, Römhild G, et al. Effect of a $40 \%$ chlorhexidine varnish on demineralization of dentin surfaces in situ. Am J Dent. 2007;20(3):193-197.

39. Brailsford SR, Fiske J, Gilbert S, Clark D, Beighton D. The effects of the combination of chlorhexidine/thymol- and fluoride-containing varnishes on the severity of root caries lesions in frail institutionalised elderly people. J Dent. 2002;30(7-8):319-324.

40. Madruga MM, Silva AF, Rosa WL, Piva E, Lund RG. Evaluation of dentin hypersensitivity treatment with glass ionomer cements: A randomized clinical trial. Braz Oral Res. 2017;31:e3. doi:10.1590/1807-3107bor2017.vol31.0003

41. Markowitz K. A new treatment alternative for sensitive teeth: A desensitizing oral rinse. J Dent. 2013;41(Suppl 1):S1-11. https://doi.org/10. 1016/j.jdent.2012.09.007

42. Mader CL, Baumgartner JC, Peters DD. Scanning electron microscopic investigation of the smeared layer on root canal walls. J Endod. 1984; 10(10):477-483. https://doi.org/10.1016/S0099-2399(84)80204-6

43. Kokkas AB, Boutsioukis ACh, Vassiliadis LP, Stavrianos CK. The influence of the smear layer on dentinal tubule penetration depth by three different root canal sealers: An in vitro study. J Endod. 2004;30(2): 100-102. https://doi.org/10.1097/00004770-200402000-00009

44. Tay FR, Pashley DH. Guided tissue remineralisation of partially demineralised human dentin. Biomaterials. 2008;29(8):1127-1137. https:// doi.org/10.1016/j.biomaterials.2007.11.001

45. Besinis A, van Noort R, Martin N. Infiltration of demineralized dentin with silica and hydroxyapatite nanoparticles. Dent Mater. 2012;28(9): 1012-1023. https://doi.org/10.1016/j.dental.2012.05.007

46. Zhang X, Neoh KG, Lin CC, Kishen A. Remineralization of partially demineralized dentin substrate based on a biomimetic strategy. J Mater Sci Mater Med. 2012;23(3):733-742. https://doi.org/10.1007/ s10856-012-4550-5

47. Pałka Ł. Ocena porównawcza obliteracji kanalików zębinowych po zastosowaniu własnej kompozycji farmaceutycznej - badania in vitro [doctoral dissertation]. Wroclaw Medical University, Poland; 2015. 